International Journal of Electrical Engineering and Technology (IJEET)

Volume 11, Issue 4, June 2020, pp. 94-99, Article ID: IJEET_11_04_010

Available online at https://iaeme.com/Home/issue/IJEET?Volume $=11 \&$ Issue $=4$

ISSN Print: 0976-6545 and ISSN Online: 0976-6553

DOI: https://doi.org/10.34218/IJEET.11.4.2020.010

(C) IAEME Publication

Scopus Indexed

\title{
AN INNOVATIVE EYE SLEEPINESS DETECTION FOR ACCIDENT AVOIDANCE AND CAUTION
}

\author{
Stephen Raj S \\ Ph.D Scholar, Department of Computer Applications, \\ VISTAS - Vels Institute of Science, Technology \& Advanced Studies, \\ Chennai, Tamil Nadu, India. \\ SriPriya $\mathbf{P}$ \\ Professor, Department of Computer Applications, \\ VISTAS - Vels Institute of Science, Technology \& Advanced Studies, \\ Chennai, Tamil Nadu, India
}

\begin{abstract}
Equipment essential for modern globe and increase the technique assist reaches a public. The vehicle technology growing their skill advanced. The motor vehicle industries has obtained latest rising with respect to protection and relieve. The driver drowsiness is one of the major causes for the accident in day-to-day life which is taking place in the real time environment. Detecting the driver drowsiness in during the driver, are done by analyzing the eye of the driver. In order to detect the drowsiness of the driver the main concept is to analyze the eye of the person, if the eye has no problem means the person is on alter or normal state. When, the eye has problem means the person is on the drowsy or fatigue state. Driving a car in the highway or on the night time in the long period of time means it is one of the complex and risky task. It is due to the driver tired and stress, the accidents occur on the highway normally. So, it is necessary that the driver should be altering while driving to avoid the crashes and accidents which make the passenger to be unsafe.
\end{abstract}

Key words: iris detection, glare extraction, drowsy detection, eye retina detection.

Cite this Article: Stephen Raj S and SriPriya P, An Innovative Eye Sleepiness Detection for Accident Avoidance and Caution, International Journal of Electrical Engineering and Technology, 11(4), 2020, pp. 94-99.

https://iaeme.com/Home/issue/IJEET?Volume=11\&Issue $=4$

\section{INTRODUCTION}

Driver accident cause by tiredness, stress, chart distraction, job heaviness, etc. needs to be predict or detect in position to escape unsafe situations and crashes. From a technical position of view present is a entail to learn the suitable indicators for finding or estimate of these driver 
status. Such indicators are also required for evaluation of the competence and value of watchfulness tactic and/or line when such driver state have been acknowledged. [5][6][9]

In the extensive run and from a levelheaded top of view, driver state pointer should be purposeful with the help of weak sensors. A camera-based system is an case of an unremarkable aerial that can provide fittingly in order and also is appropriate for automobile driver function. As of a advanced camera-based plan, it is probable to get in organize and we don't hang around for the first responders sent to the picture, by itself we can keep lives. diminish the wait amid accident rate and use in-vehicle repeated accident on for occurrence head and gaze way, eye cover gap and facial lingo. In position for a way of carrying grow camera design to full fill its motivation, it has to get together auto-motive materials in situation of steadiness and collide merit and it hold to also be capable to turn into familiar to a diversity of glow situation and to a wide variety of facial covering and anthropometric actions. top camera technique for head and seem tracking are moderately posh and thus not likely to utilize for client purpose. Nor are they apposite to use in low funds cram or no classified research where no analysis head is there (e.g. naturalize heavy reading) as they often necessitate objective shift and confirm.[8][7][5]

The growing concentration in compute driver position hoist the need for a worth prepared camera based the schemes that can be ready-to-wear and old in safekeeping system or for learning rationale such as key position standing by test or in squat end demonstration. [4]

A low downward speed camera based scheme urn be insert and cast-off in the bulk type of driver concert revision. This resolve did not just increase the in sequence on driver routine but also makes easy evaluation of have a row starting e.g. disparate profound demos.[3][4][1][20]

In the up to date hear, the key center be on driver tiredness. Driver amusement was suspicious to several level.[1]

\section{AIMS AND RESTRICTIONS}

The major aims of the research were to:

- Expand a little value eye gaining unit for eye track based statistics.

- Identify the achievable meter (camera-based and other) of driver tiredness and intermission.

- Recognize and verify the camera based the pointer of driver tiredness in a pasture site using a demonstration automobile.

- Look at the arrangement of the pointer as tiredness detectors.

- Increase a stupor classifier for serious demo (that can be used in prospect study to plan to charge e.g. sleepiness concern border).

A plagiaristic sketch was to formulate a heading with driver complaint in series (drowsiness and disruption) from jointly field and demonstration experiment The file is prospect to be hand-me-down for supplementary psychiatry in outlook study.[9]

They were mostly planned as lethargy experiment with one alert circumstance (morning) and one sleepy position (at night), but in the closing stages of the harsh session an disturbance occasion occur, which can be used in view analysis on driver disruption. The novel training was also well appropriate for demo good reason, while the similar topic participate in both trials. though demo corroboration was not a part of the current study, some procedures and a review were added to the test in order to make available a helpful data-set for viewpoint demo good reason.[8][1][2] 


\section{EYE RETINA DATA ACQUISITION}

double tidy Eye retina method were install in the car and the expression: the camera picture method that was to be assessment and a camera tidy Eye authority (case incidence $50 \mathrm{~Hz}$ ) who was second-hand as an compass reading process afford picture based sight fact. The 1camera classification was the accrue as tiny as likely last the direction-finding wheel, in the car on top of the fleece of the (variable) steering article plus in the demo at the minor edge of the main device. The camera array was rising to top of the deal with panel down with dual flash and in step to the camera telephone hit so as to by somewhat rough it's have point of burn and call, the possess glow sub system would not clutch the back with each extra. The positions of the cameras family member to the car be quality- ted. evenly camera methods be put up to concomitantly proof time-stamped raw videocassette to firm disk drive, by lossless thickness. The recording from the inspection drives was collected and then process with no gesture.[7][9][10]

Corporeal data -camera scanner was documentation by a Vita harbor 4 with 256.

Everybody in order achievement method was linked to every extra in arranges to help group of numbers.[10]

Table 1 Number of accurate, negative and missed eye retina detections in nighttime

Iris scanner Camera right Camera left

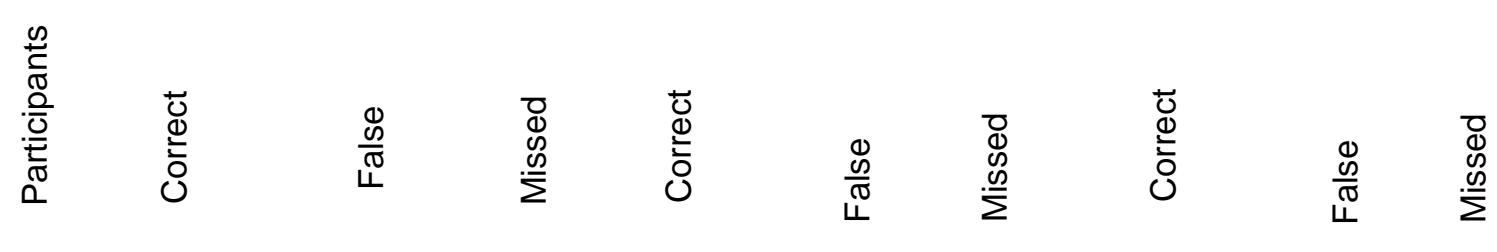

\begin{tabular}{|c|c|c|c|c|c|c|c|c|c|}
\hline 1 & 13 & 0 & 1 & 4 & 0 & 1 & 14 & 0 & 0 \\
\hline 2 & 22 & 0 & 1 & 27 & 1 & 1 & 38 & 0 & 1 \\
\hline 3 & 25 & 0 & 0 & 5 & 0 & 3 & 16 & 0 & 2 \\
\hline 5 & 15 & 1 & 0 & 1 & 0 & 1 & 2 & 0 & 2 \\
\hline 7 & 15 & 2 & 0 & 20 & 1 & 0 & & & \\
\hline 8 & 33 & 0 & 0 & 16 & 11 & 1 & 33 & 0 & 1 \\
\hline 9 & 19 & 1 & 0 & 4 & 0 & 2 & 24 & 0 & 10 \\
\hline 10 & 59 & 0 & 1 & 17 & 0 & 1 & 20 & 0 & 1 \\
\hline 11 & 19 & 0 & 0 & 1 & 0 & 0 & 29 & 0 & 0 \\
\hline 12 & 48 & 0 & 0 & 0 & 0 & 0 & 4 & 2 & 2 \\
\hline 13 & 40 & 0 & 2 & 9 & 0 & 3 & 27 & 1 & 1 \\
\hline 14 & 14 & 1 & 2 & 2 & 0 & 2 & 1 & 1 & 2 \\
\hline 16 & 21 & 1 & 0 & 9 & 9 & 1 & 10 & 0 & 1 \\
\hline 17 & 34 & 1 & 0 & 5 & 0 & 2 & 27 & 9 & 1 \\
\hline 18 & 9 & 0 & 1 & 0 & 8 & 1 & & & \\
\hline 19 & 35 & 2 & 0 & 0 & 0 & 3 & 31 & 4 & 0 \\
\hline 20 & 35 & 0 & 0 & 14 & 0 & 2 & 28 & 5 & 0 \\
\hline $\begin{array}{l}\text { Night } \\
\text { Time }\end{array}$ & 446 & 10 & 7 & 134 & 30 & 24 & 304 & 22 & 25 \\
\hline
\end{tabular}

\section{EYE RETINA IMAGE DROWSSINESS THRESHOLD}

Image occurrence is not just associated to sleepiness but also to the share of see capital, the control point in order treat and perhaps treat form and is as a outcome, not a extremely of use examination of tiredness although, as it reflect the power of underprivileged eye retina detections form it is an nice-looking presentation stick of the unlike methods. How the heart price and the quartiles of the conventional eye retina frequency vary more time. It jug be see that for every methods, the eye retina frequency is moderately solid all through the whole trip 
during day-light while it tend to augment with wintriness driven during of the night. There is, though, a large difference flanked by the methods. The usual eye retina frequency diagonally all in turn and all applicant are 12 eye retinas per min for the IRIS, 15eye eye retina per-min for the camera method and 15 eye eye retina per-min for the camera method.[10][1].

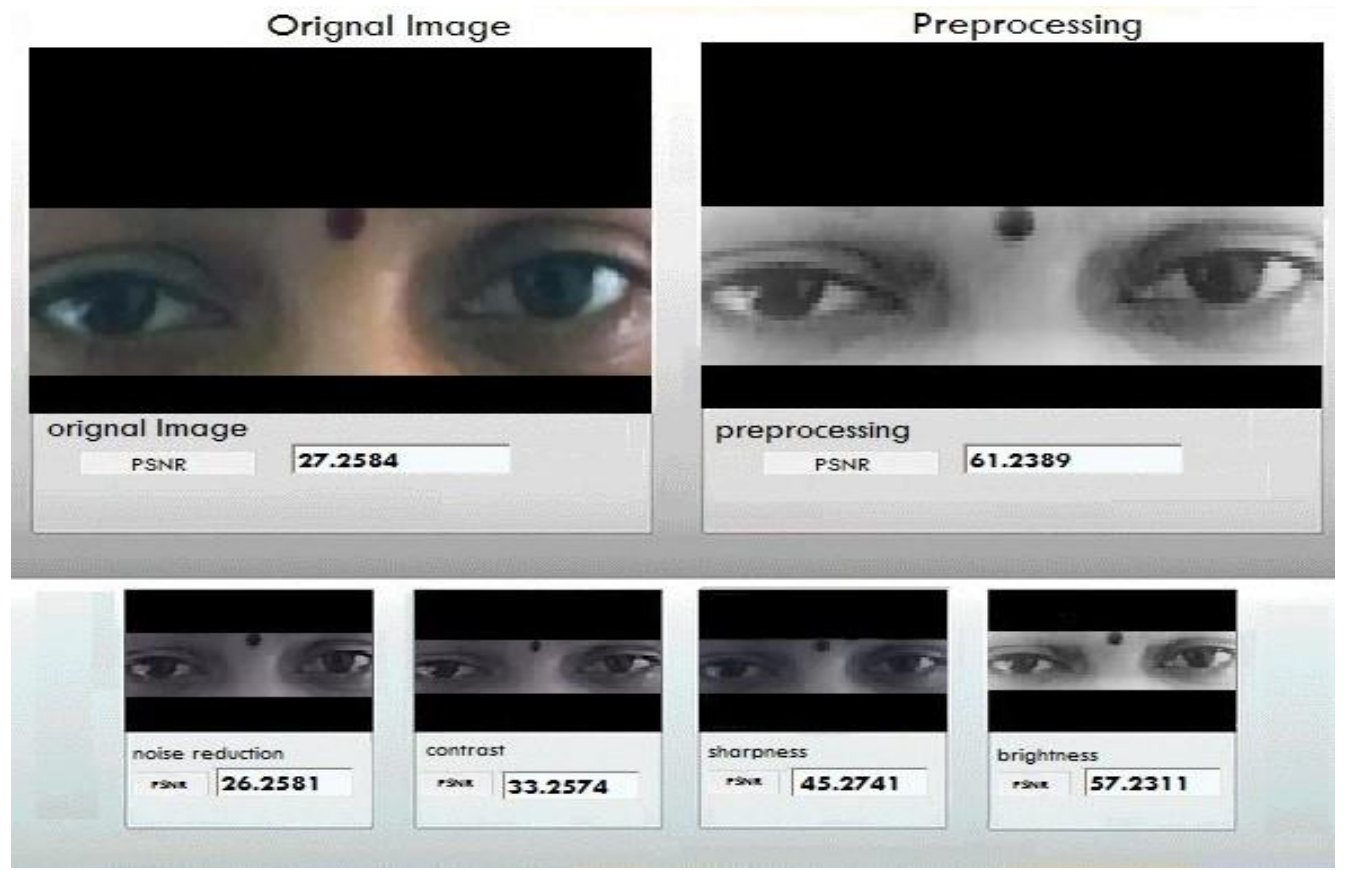

Figure 1 Result of iris scanner eye images for preprocessing

Conspiracy the difference in normal eye retina occurrence, flanked by eye retinas linked with KSSS for each partner illustrate that for relating to partly of the member the eye retina incidence augment when they are sleepy whilst the extra halve show a cut in eye retina velocity, the member have been sort in hiking order according to the IRIS. Preferably there be theoretical to have been a alike increasing tendency in all three technique but there is no family member flank by the eye eye retina detections of the method. The best threshold was important now by pace from surface to face the variety of pointer principles and in each step devious sympathy, specificity and look. Data tip were look upon as "tired" as the rest was look upon as "helpful”.[1][5]

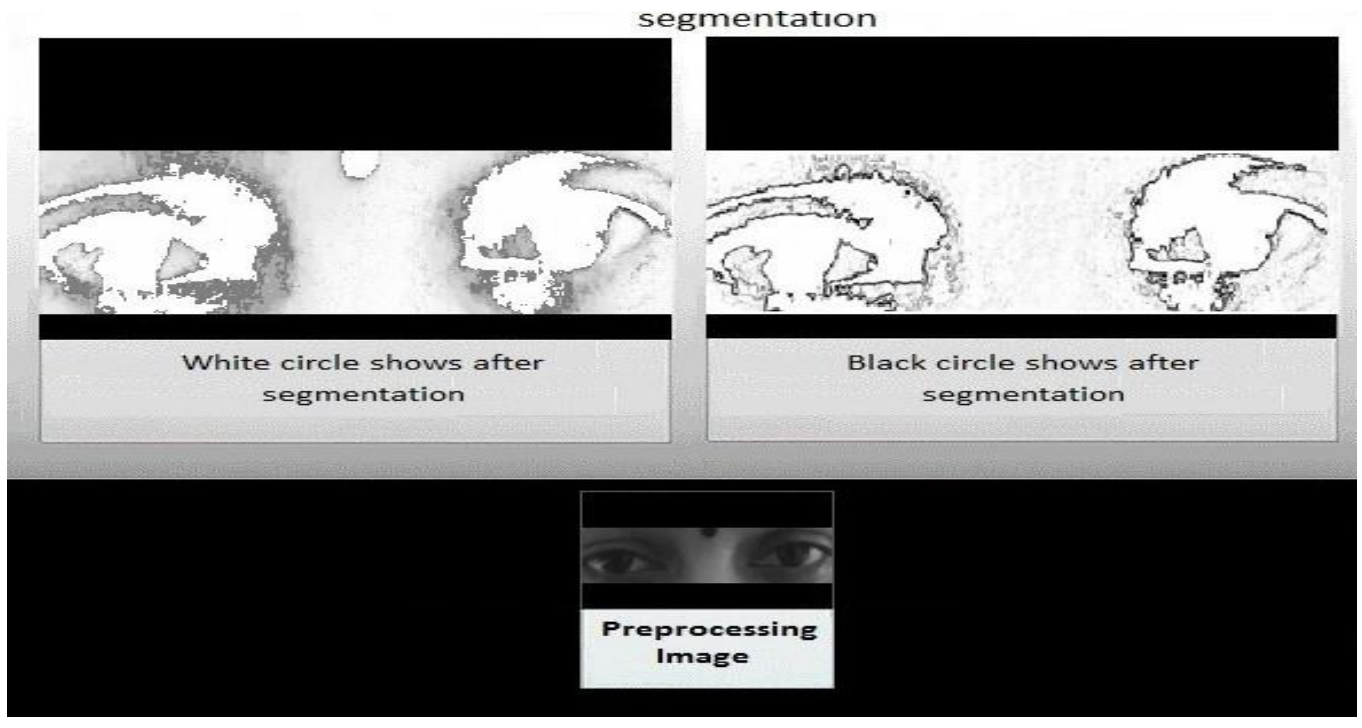

Figure 2 Result of iris scanner eye images for segmentation 
The eye retina era varies from eye eye retina to image. It is so customary to communal the eye eye retina age in small juncture skylight in sort to insert to the stoutness. This aggregation can be achieve in more than a few habits. The most often used eye retina stage gauge is perhaps mean eye retina stage. Option measures are, for model, hub (less approachable to outliers) or max (hub on lengthy eye retina). Here four dissimilar eye retina periods based events were investigate: mean the eye retina period, center eye retina period, mean of $10 \%$ best eye retina and slight bit of eye retina longer than $0.10 \mathrm{~s}$. The best doorstep for judicious between $\mathrm{KSSS} \geq 10$ and $\mathrm{KSSS}<09$ and the same look for each work out

The presentation of the eye retina proceedings unaccompanied is quite levelheaded. It appears like the eye retina events from the camera technique have rather better presentation than the proceedings from the IRIS on sprint of the crush. yet, it is hypothetical to be renowned that there are difference in the primary data-sets, since camera information is completely gone astray from three inspiring sitting.[5][9]

For the camera process all four events have the comparable act, while for the IRIS, the dual events connected to the long eye retina have the best presentation. The part of the eye retina $>0.12 \mathrm{~s}$ (eye retina) been elected as a key to the classify, since it had the best piece for the camera manner and the next best for the IRIS.[9][2]

Table 2 Threshold and performance for position measures.

\begin{tabular}{l|cc}
\hline \multicolumn{1}{c|}{ Measurements } & Thresholds & Performance \\
\hline Position & 1.7 & 0.74 \\
line crossings & 0.50 & 0.65 \\
The Maximum line exceed & $0.006 \mathrm{~m}$ & 0.65 \\
stripe way area & $0.54 \mathrm{~m} \times \mathrm{s}$ & 0.63 \\
\hline
\end{tabular}

\section{RESULT DETECTS DESTRACTION POSITION}

Artifacts are frequently seen, since of activities, changes in posture, gaping, etc., which perhaps can comprise a consequence on eye retina finding. [1][10][5][9]

Table 3 Performances for preparation data for the iris base and the camera-base

\begin{tabular}{c|cc}
\hline $\begin{array}{c}\text { Limit (minimum no } \\
\text { of cases per limb) }\end{array}$ & \multicolumn{2}{|c}{ Presentation Data } \\
3(def) & 0.91 & 0.89 \\
11 & 0.84 & 0.80 \\
21 & 0.80 & 0.69 \\
31 & 0.82 & 0.80 \\
41 & 0.84 & 0.71 \\
51 & 0.85 & 0.70 \\
\hline
\end{tabular}

\section{CONCLUSION}

Inside the arrangement of their hunt a near to the soil rate eye and stare at track camera method was built-up and realize in a test car and in the VT authoritative demo. The inscription assessment resulted in a list of the realistic gauge for tiredness detection.[10][1]

The designate eye retina incidence, and eye retina era was the realize in the camera method and evaluate on in order from the field assessment. It was recognized to the method fail to spot heaps of the eye retina and that the eye retina stage was not in concurrence with the eye retina epoch find from the IRIS and as of a compass reading camera method. Conversely, the penalty also specify that it be invented to be liable to get healthier the eye retina exposure algorithm in the demonstration low down price camera technique since the 
uncommon data look well in a lot of luggage where the algorithm catastrophic to forename eye retina.[6][5]

The final set of indicator were an expected eye retina value with the plan base on the value the motor vehicle handler report before the weighty session, normal deviation of side put and part of the eye retina $>0.10 \mathrm{~s}$ ( Eye retina; IRIS based and the effective camera based).

\section{REFERENCES}

[1] Shailesh Bhavthankar, Prof. H.G.Sayyed, (2015) "Wireless System for Vehicle Accident Detection and Reporting using Accelerometer and GPS", International Journal of Scientific \& Engineering Research, Volume 6, Issue 8.

[2] Md.Towhid Chowdhury, Ebad Zahir,"Automotive Parking Lot and Theft Detection through Image Processing", American Journal of Engineering Research (AJER) Volume02, Issue-10, pp-308-313

[3] Indu R. Nair, Nadiya Ebrahimkutty, Priyanka B.R., Sreeja M, Gopu Darsan, (2017) "Smart System for Drowsiness and Accident Detection", International Journal of Computer Science Trends and Technology (IJCST) - Volume 5 Issue 3, May - Jun

[4] M.Yogavalli, E.Arulmozhi, M.Rajeswari and Mr.V. VijayaKumar, "Review on Detecting and Handling Traffic Violation", International Journal of Trend in Research and Development, Volume-2(5).

[5] Mrs Manasi Patil, Aanchal Rawat, Prateek Singh, Srishtie Dixit, (2016) "Accident Detection and Ambulance Control using Intelligent Traffic Control System", International Journal of Engineering Trends and Technology - Volume 34 Number 8.

[6] Stephen raj. S, Sripriya. P An inventive arrangement for accident prevention detection and caution using image mining, International Journal of Engineering \& Technology, 7 (2.33) (2018) 657-659

[7] Stephen Raj .S, Sri Priya .P, (2017) Automatic Vehicle Detection Using gps and Challenges in Image Processing, International Journal of Civil Engineering and Technology, volume 8, issue 11, pp. 287-293.

[8] Stephen Raj. S, Sripriya. P, (2018) Accident Prevention Eye Tiredness Detection Using Image Mining, International Journal of Mechanical and Production Engineering Research and Development, vol. 8, issue 2, 363-368.

[9] Stephen, R.S., Sripriya, P. (2019) “Actual Moment Driver Lethargy Experience Based on Driver's Face Picture with the SRS System " in "Proceedings of the International Conference on Machine Learning, Big Data, Cloud and Parallel Computing: Trends, Prespectives and Prospects, COMITCon “,423-428.

[10] Jaeik Jo, Ho Gi Jung, Kang Ryoung, Jaihie Kim, (2012) "Vision -based method for detecting driver drowsiness and distraction in driver monitoring system", in Proc. Optical Engineering, vol . 15, no.12. 